\title{
ПОЛИЦЕЙСКОЕ ПРАВO
}

Безруков А.В.

\section{УЧАСТИЕ ПРАВООХРАНИТЕЛЬНЫХ ОРГАНОВ И ОРГАНОВ МЕСТНОГО САМОУПРАВЛЕНИЯ В ОБЕСПЕЧЕНИИ ПРАВОПОРЯДКА В РОССИИ}

\begin{abstract}
Аннотация. Предметом исследования являются вопросы функционирования и взаимодействия правоохранительных органов и органов местного самоуправления в конституционно-правовом механизме обеспечения правопорядка. Обращается внимание на основные направления взаимодействия органов государственной власти, органов местного самоуправления и правоохранительных органов. Особо показана роль органов внутренних дел и органов местного самоуправления в реализации функции обеспечения правопорядка, раскрыты основные направления, формы и принципы их взаимодействия. Автор доказывает, что правоохранительные органы способны эффективно обеспечить надлежащий правопорядок во взаимодействии с другими государственными и местными органами. Исследование проводится на основе общенаучных и частнонаучных методов, применяются методы формальной логики, сравнительно-правовой, анализа и синтеза. Основными выводами проведенного исследования являются суждения о том, что в конституционно-правовом механизме обеспечения правопорядка задействованы практически все органы публичной власти, исходя из конституционного предназначения особая роль принадлежит правоохранительным органам и органами местного самоуправления. Эффективность обеспечения правопорядка достигается при условии их слаженного взаимодействия.
\end{abstract}

Ключевые слова: правопорядок, обеспечение правопорядка, правоохранительные органы, органы местного самоуправления, эффрективное взаимодействие, Президент, полиция, прокуратура, государственные органы, координация.

Review. The subject of the research is the range of issues of functioning and interaction of law enforcement bodies and bodies of local government in the constitutional legal mechanism of the rule of law provision. The author emphasizes the main directions of interaction of bodies of state power, local authorities and law enforcement agencies, particularly, the role of internal affairs bodies and bodies of local authorities in the implementation of the functions of law enforcement, basic directions, forms and principles of their interaction. The author argues that law enforcement agencies are able to effectively provide adequate law and order in cooperation with other state and local agencies. The study is based on the general and specific scientific methods, methods of formal logic, comparative law, analysis and synthesis. The main conclusions of the research are the judgments that almost all bodies of public authorities are involved in the constitutional legal mechanism of the rule of law provision, and the leading role belongs to law-enforcement bodies and local authorities. The effectiveness of law enforcement activities is achieved through their interaction.

Keywords: police, President, effective interaction, local authorities, law enforcement agencies, law enforcement, rule of law, the Prosecutor's office, public authorities, coordination.

O беспечение правопорядка является важнейшей функцией и задачей государства, в реализации которых участвуют практически все органы публичной власти. Правопорядок есть цель правового регулирования, его результат, для его обеспечения издаются правовые и правоприменительные акты, формируется конституционноправовой механизм его обеспечения органами публичной власти, в котором особое место занимают правоохранительные органы и органы местного самоуправления. И если на первые задача обеспечение правопорядка ложится исходя из их специального предназначения и правоохранительных функций, то на вторые такое полномочие возложено Конституцией РФ (ч. 1 ст. 132).

В механизме обеспечения правопорядка в той или иной мере участвуют все органы публичной власти, но основную нагрузку по обеспечению правопорядка несут все же органы исполнительной власти, включая правоохранительные структуры. Однако правоохранительные органы как специализирующиеся в отдельных сферах деятельности органы, не всегда способны эффективно обеспечить надлежащий правопорядок, поэтому важно организовать их конструктивное сотрудничество не только друг с другом и органами местного са- 


\section{Административное и муниципальное право 10 (94) • 2015}

моуправления, но и с законодательными органами власти, роль которых в обеспечении правопорядка порой не учитывается должным образом. Именно законодательные органы и депутатский корпус посредством принятия необходимых правовых предписаний и путем активизации правоохранительных органов по конкретным делам (запросы, обращения, представления), проведения парламентско-контрольных мероприятий, в значительной степени способствуют восстановлению, укреплению и качественно эффективному обеспечению правопорядка [1].

Правоохранительные органы занимают значимое место в деятельности по обеспечению правопорядка, их особая роль (МВД, ФСБ, ФСИН и др.) проявляется в обеспечении правопорядка и безопасности в ситуациях чрезвычайного характера (террористические акты, аварии, катастрофы, массовые беспорядки), когда прямой угрозе подвергаются жизнь, здоровье, права и свободы граждан, что влечет необходимость правоохранительным органам компетентно и своевременно принять меры по защите конституционных прав граждан и обеспечению правопорядка. Именно профессионально, качественно и согласованно выполненный комплекс мероприятий правоохранительными органами в различно складывающихся ситуациях, позволит обеспечить реализацию положений Конституции РФ, гарантирующих соответствующие права и свободы личности, обеспечение законности и правопорядка в Российской Федерации.

Особо значима роль органов внутренних дел, которые посредством определенных форм и методов, осуществляют различные виды деятельности (административная, оперативно-розыскная, предварительное следствие, дознание) как взаимосвязанные и взаимообусловленные направления деятельности, общая цель которых сводится к обеспечению правопорядка, конституционных прав и свобод граждан [2]. Поэтому весьма значимы фундаментальные исследования государственно-правовых и организационных аспектов функционирования МВД России как субъекта правоохранительной деятельности и обеспечения правопорядка [3], выявление роли полиции в обеспечении правопорядка [4].

Следует обратить внимание, что эффективность деятельности органов внутренних дел во многом обусловлена качественно отлаженным сотрудничеством с другими государственными органами и органами местного самоуправления. Так, в период избирательных кампаний особую значимость приобретает эффективно выстроенный механизм взаимодействия органов внутренних дел и избирательных комиссий, которые осуществляют совместную организационно-правовую дея- тельность по созданию «оперативного штаба сил правопорядка», участию в мероприятиях по технической обеспеченности и антитеррористической защищенности зданий и помещений избирательных участков и комиссий $[5,6,7]$. При этом, взаимодействие полиции и избирательных комиссий должно строится на принципах невмешательства полиции в избирательный процесс; безвозмездности; приоритетности прав и свобод граждан; учете общегосударственных и местных особенностей; своевременности и оперативности реагирования на избирательные правонарушения; согласованности действий органов внутренних дел и избирательных комиссий [5, с. 34-36].

Полицией применяются разные правовые и не правовые формы обеспечения правопорядка при организации и проведении выборов и референдума (охрана правопорядка на избирательных участках, обеспечение сохранности и безопасности при перевозке избирательных документов, привлечение специалистов и экспертов полиции к работе в составе КРС и рабочих групп избиркомов, участие в комиссиях по обследованию зданий и помещений участковых избиркомов, заключение соглашений с избиркомами, привлечение к юридической ответственности участников избирательного процесса за совершение правонарушений и др.) [5, с. 39-40].

Не менее значимым является обеспечение эффективного взаимодействия органов внутренних дел с органами местного самоуправления как их совместной деятельности, направленной на обеспечение безопасности, правопорядка и реализацию конституционных прав граждан, проживающих в соответствующих муниципальных образованиях. Среди основных направлений такого взаимодействия выделяют: обмен информации о состоянии правопорядка и мероприятиях по его обеспечению; совместная разработка комплексных целевых программ и проведение отдельных мероприятий; формирование в полиции и органах местного самоуправления подразделений, ведающими вопросами их взаимодействия по обеспечению правопорядка на территории муниципалитета [8, с.11]. Так же значимы такие формы их сотрудничества как проведение совместной профилактической работы, заслушивание отчетов должностных лиц по вопросам обеспечения правопорядка [7]. Но в любом случае в современных условиях нельзя говорить о подчиненности органов внутренних дел, функционирующих на районном уровне, главам муниципальных образований и муниципальным органам $[8$, с. $55-$ $62]$, следует вести речь о возможности их конструктивного взаимодействия и сотрудничества.

Другой вопрос - в каком нормативном документе должно быть регламентировано такое взаимодействие? Иногда оно регулируется в уставах 
муниципалитетов, что опять влечет проблему, связанную с тем, что ОВД не могут руководствоваться муниципальными нормативными правовыми актами и не несут ответственность перед органами местного самоуправления. Возможно, следует реализовать давно предлагаемую идею о принятии Ф3 об основах взаимодействия органов государственной власти и органов местного самоуправления $[8$, с. 10,24$]$.

В любом случае значение такого сотрудничества нельзя принижать. Актуален сегодня и тезис о том, что органы внутренних дел являются одним из инструментов реализации государственной политики в сфере обеспечения правопорядка, но без участия других государственных органов и органов местного самоуправления система органов внутренних дел не способная эффективно осуществлять возложенные на нее функции, обеспечивающие безопасность и правопорядок [8, с. 74-75].

Таким образом, согласованная деятельность органов внутренних дел с другими органами государственными органами и органами местного самоуправления является объективной потребностью государственно-правового развития России, способствует укреплению правопорядка в России.

Другим важнейшим условием эффективного обеспечения правопорядка является слаженная и скоординированная работа всех правоохранительных органов, которые должны согласованно функционировать и взаимодействовать как между собой, так и с другими органами публичной власти. Правовой основой для этого является Указ Президента РФ от 18 апреля 1996 года № 567 «0 координации деятельности правоохранительных органов по борьбе с преступностью», который определил как примерный перечень правоохранительных органов (оставляя его открытым), так и основные направления координационной деятельности таких органов, среди которых совместный анализ состояния преступности; выполнение федеральных и региональных программ борьбы с преступностью; подготовка и направление информационных материалов по вопросам борьбы с преступностью Президенту РФ, Федеральному Собранию РФ и Правительству РФ, органам государственной власти субъектов РФ, а также органам местного самоуправления и др.

Одной из основных форм координационной деятельности правоохранительных органов являются координационные совещания, созываемые под руководством соответствующих прокуроров, что предусмотрено ч. 1 ст. 8 Ф3 «О прокуратуре Российской Федерации», устанавливающей, что деятельность правоохранительных органов по борьбе с преступностью координируют Генеральный прокурор РФ и подчиненные ему прокуроры. По особо резонансным делам такие совещания проводятся под руководством Президента РФ, что свидетельствует о его ключевой роли в государственном механизме и обеспечении консолидированной работы всех органов государственной власти, включая правоохранительные структуры, в направлении обеспечения государственного единства и правопорядка.

Таким образом, имеются достаточные правовые основания для консолидированной работы всех органов публичной власти, включая правоохранительные структуры и органы местного самоуправления, в направлении обеспечения правопорядка.

В осуществлении координационной функции правоохранительных органов по обеспечению правопорядка возрастает роль высших должностных лиц субъектов РФ. Президентом РФ издан Указ от 11 декабря 2010 года № 1535 «0 дополнительных мерах по обеспечению правопорядка», согласно которому главам регионов в целях совершенствования деятельности по обеспечению правопорядка предписано создать постоянно действующие координационные совещания по обеспечению правопорядка в субъектах Российской Федерации и утвердить их состав.

Основными задачами координационных совещаний являются:

а) обобщение и анализ информации о состоянии правопорядка в субъектах Российской Федерации, а также прогнозирование тенденций развития ситуации в этой области;

б) анализ эффективности деятельности территориальных органов Министерства внутренних дел Российской Федерации и территориальных органов иных федеральных органов исполнительной власти, органов исполнительной власти субъектов Российской Федерации и органов местного самоуправления по обеспечению правопорядка в субъектах Российской Федерации;

в) разработка мер, направленных на обеспечение правопорядка в субъектах Российской Федерации;

г) организация взаимодействия территориальных органов федеральных органов исполнительной власти, органов исполнительной власти субъектов Российской Федерации и органов местного самоуправления, а также указанных органов с институтами гражданского общества и социально ориентированными некоммерческими организациями по вопросам обеспечения правопорядка в субъектах Российской Федерации.

Практика реализации указанного документа выявила позитивные аспекты, которые вырази- 


\section{Административное и муниципальное право 10 (94) • 2015}

лись в том, что координационные совещания по обеспечению правопорядка вырабатывают и принимают решения стратегического характера в сфере обеспечения правопорядка в субъектах Федерации, совершенствуют взаимодействие органов государственной власти, местного самоуправления, правоохранительных органов и повышают эффективность организационно-системных мер к решению задач в сфере борьбы с преступностью[10].

Вместе с тем, рассматриваемый документ не унифицирует и не конкретизирует состав участников координационных совещаний, тем самым предоставляет главам субъектов РФ обширные возможности по определению состава участников этих совещаний. И практика показала разнообразие подходов на местах при определении состава их участников, в некоторых регионах органам прокуратуры приходилось отстаивать позицию по решению вопроса о включении в состав таких совещаний, как руководителя территориальной прокуратуры, так и руководителей иных правоохранительных органов. Так, в Нижегородской области, по мнению правительства области, включение прокурора в состав координационного совещания не было обязательным, и только по настойчивой позиции Генеральной прокуратуры РФ указом губернатора области прокурор был введен в состав координационного совещания по обеспечению правопорядка. В Архангельской области по инициативе прокуратуры области дополнительно включены руководители следственного управления Следственного комитета РФ по Архангельской области и Ненецкому автономному округу, управления Федеральной миграционной службы по области, транспортный прокурор, военные прокуроры гарнизонов $[10,11]$.

Таким образом, в субъектах РФ вопрос формирования персонального состава участников постоянно действующих координационных совещаний по обеспечению правопорядка решается неоднозначно и требует унификации в виде нормативной конкретизации состава участников таких совещаний.

Исторический опыт показывает, что практика создания подобных структур, укрепляющих взаимодействие государственных органов общей компетенции и правоохранительных органов, появилась еще в советское время. Обратившись к недавнему советскому прошлому, можно обнаружить, что помимо правоохранительных органов определенные обязанности по противодействию преступности и обеспечению правопорядка возлагались на органы государственной власти на местах с активным участием партийных органов [12].

Так, постановление ЦК КПСС и Совета Министров СССР от 23 июля 1966 г. № 571 «0 мерах по усилению борьбы с преступностью» прямо обязы- вало ЦК компартий союзных республик, крайкомы и обкомы партии, Советы министров союзных и автономных республик, исполкомы краевых и областных Советов депутатов принимать решительные меры к наведению образцового общественного порядка в населенных пунктах, систематически и глубоко анализировать положение с преступностью, улучшать руководство деятельностью органов охраны общественного порядка, прокуратуры и суда, осуществлять общественный контроль за выполнением решений об усилении борьбы с преступностью [13]. Причем эти решения получали конкретную реализацию на практике[12, с. 41-42].

Что касается органов местного самоуправления, то необходимость его выделения очевидна, поскольку функция охраны правопорядка, как отмечалось, закреплена в ч.1 ст. 132 Конституции РФ именно за органами местного самоуправления, что свидетельствует о реализации такого полномочия не только государственными, но и местными органами публичной власти. Следовательно, обеспечение правопорядка является важнейшей конституционной задачей органов местного самоуправления. Однако пока нам представляется преждевременным перенимать западный опыт, где в обеспечении правопорядка ведущая роль принадлежит органам местного самоуправления, которые выполняют функцию обеспечения правопорядка как часть общегосударственной задачи, но в пределах конкретного муниципального образования [8, c. 99-106].

Ученые справедливо обращают внимание на необходимость реализации нормы ст. 132 Конституции РФ: органы местного самоуправления самостоятельно осуществляют охрану общественного порядка, что на практике реализуются полицией [14].

Конституционное положение о том, что органы местного самоуправления осуществляют охрану общественного порядка, конкретизируется в Федеральном законе от 6 октября 2003 года № 131-Ф3 об общих принципах организации местного самоуправления, согласно которому организация охраны общественного порядка на территории муниципального района и городского округа муниципальной милицией отнесена к числу вопросов местного значения муниципального района (п. 8 ч.1 ст.15 Закона) и городского округа (п. 9 ч. 1 ст. 16 Закона).

На практике функциональная деятельность органов местного самоуправления в правоохранительной сфере в настоящее время сводится к организационному обеспечению деятельности по охране правопорядка, что проявляется в том, что они:

1) принимают участие в координации деятельности правоохранительных органов; 
2) создают правоохранительным органам необходимые условия для более результативной работы;

3) формируют в соответствии с законодательством муниципальные органы охраны общественного порядка;

4) принимают участие в комплексном планировании противодействия преступности;

5) формируют правоохранительные комиссии и контролируют их деятельность;

6) через общественные советы осуществляют контроль за деятельностью территориальных органов внутренних дел (ч. 7 ст. 9 и ч. 4 ст. 50 Ф3 о полиции) [15].

Законодателем и в прежнем, и действующем ФЗ об общих принципах организации местного самоуправления в РФ закреплена возможность создания муниципальной милиции, но для этого до сих пор не принимаются соответствующие законодательные акты, хотя такая идея, как и идея обеспечения рационального перераспределения функций и правомочий в сфере управления системы МВД России на федеральном, региональном и муниципальном уровнях, выдвигается не первый десяток лет [3, с. 13, 288-289;

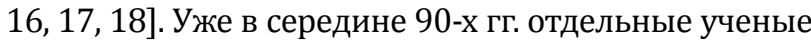
предлагали принятие федерального закона «0 полиции» и создание региональных и муниципальных органов охраны правопорядка [19].

Современные исследователи, предлагая формировать муниципальную милицию на основе существующих объединений по охране общественного порядка, подчеркивают, что муниципальная милиция не может и не должна подменять собой федеральную полицию, ее основными функциями должны быть охрана общественного порядка и профилактика правонарушений на территории муниципального образования. Деятельность муниципальной милиции должна регламентироваться Федеральным законом «О муниципальной милиции» и законами субъектов РФ[20].
Другими авторами обоснованно указывается на необходимость дополнения Ф3-131 об общих принципах местного самоуправления положениями, раскрывающими содержание основных полномочий органов местного самоуправления в сфере обеспечения правопорядка как вопросов местного значения, а конкретные полномочия органов местного самоуправления в сфере обеспечения правопорядка предлагается закреплять в уставах муниципальных образований в соответствии в федеральными законами и законами субъектов РФ $[15$, с. $163-164]$.

Видится, что с возрастанием ответственности местной власти за состояние правопорядка и законности на территории муниципалитетов, представляется необходимым принятие ФЗ «0 муниципальной милиции», в котором следует определить формы участия органов местного самоуправления в охране правопорядка.

Однако с учетом того, что в ФЗ от 7 февраля 2011 года «0 полиции» развивается идея централизации полиции (ч. 1 ст.4 ФЗ о полиции) с переходом всей полиции на федеральное бюджетное финансирование (ч.1 ст. 47 ФЗ о полиции), что исключает двойное подчинение полиции, на современном этапе такой подход означает отказ законодателя от идеи создания муниципальной полиции [15, с. 165-166]. Поэтому, в дальнейшем потребуется корректировка закона о полиции в целях формирования возможности создания муниципальной милиции.

Таким образом, в конституционно-правовом механизме обеспечения правопорядка задействованы практически все органы публичной власти, однако именно эффективность функционирования и слаженность взаимодействия правоохранительных органов и органов местного самоуправления во многом определяют качественное состояние правопорядка и результативность его обеспечения органами публичной власти в целом.

\section{Библиография:}

1. Безруков А.В. Конституционно-правовые аспекты осуществления законодательной власти по обеспечению правопорядка в России: монография. М., 2015. С. 3-43

2. Виссаров А.В. Правопорядок и субъекты его обеспечения (теоретико-правовой аспект): автореф. дис.... канд. юрид. наук. М., 2003. С. 17-18.

3. Зубов И.Н. Государственно-правовые и организационные проблемы функционирования и развития системы МВД России: дисс. ... докт. юрид. наук. СПб, 1999. С. 9-10.

4. Правовое положение полиции МВД России: учебник / под ред. Ф.П. Васильева. М., 2014. С. 258-268.

5. Чистобородов И.Г. Административно-правовое обеспечение органами внутренних дел правопорядка и общественной безопасности в период подготовки и проведения избирательных кампаний: дис. ... канд. юрид. наук. M., 2013. С. 13-14

6. Красинский В.В. Правовое обеспечение защиты конституционного строя России в избирательном процессе: монография. М., 2010. С. 161-162.

7. Федотова Ю.Г. Контрольные полномочия избирательных комиссий в механизме обеспечения безопасности Российской Федерации // Государственная власть и местное самоуправление. 2015. № 2. С. 34-36.

8. Переверзев Е.А. Правовые и организационные основы взаимодействия органов внутренних дел и органов местного самоуправления: дис. ... канд. юрид. наук. М., 2001. 


\section{Административное и муниципальное право 10 (94) • 2015}

9. Скрипкина Ю.Г. Взаимодействие органов местного самоуправления с органами внутренних дел по охране общественного порядка на территории муниципального образования: конституционно-правовые и организационные вопросы: автореф. дис. ... канд. юрид. наук. СПб., 2009. С. 25-26.

10. Совместное информационное письмо Генеральной прокуратуры России, МВД России, ФСБ России, Следственного комитета России, ФСКН России и ФТС России от 5 октября 2012 г. N 32/1/9016/8/К/8-4451/208-35208/ ВИ-4351/01-40/50159 // СПС Консультант Плюс.

11. Ступаченко Е.В. Состав участников постоянно действующих координационных совещаний по обеспечению правопорядка в субъектах РФ // Законность. 2014. № 7.

12. Ступаченко Е.В. Исторические и правовые аспекты создания постоянно действующих координационных совещаний по обеспечению правопорядка в субъектах Российской Федерации // Государственная власть и местное самоуправление. 2014. № 11. С.40-41.

13. Сборник приказов и инструкций Генерального прокурора СССР. Часть 1. М., 1976. С. 37.

14. Фадеев В.И. Стабильность и развитие Конституции Российской Федерации // Вестник Московского университета. Серия 11. Право. 2014. № 1. С.52-53.

15. Скрипкин Г.Ф. К вопросу об охране общественного порядка органами местного самоуправления в свете принятия Закона о полиции // Вестник Московского университета МВД России. 2012. № 1. С. 165-166.

16. Миньковский Г.М. О понятии и структуре муниципальной милиции // Муниципальная милиция: проблемы организации и правового обеспечения, зарубежный опыт. М., 1991. С. 35-37.

17. Старостин С.А. Нужна ли муниципальная милиция Российской Федерации // Научный портал МВД России. 2014. №4. C. 80-82.

18. Шихов Е.Ю. Организация местной (муниципальной) милиции в системе управления (по материалам города Москвы): дисс. ... канд. юрид. наук. М., 1995. С.7-10.

19. Х Харитонов А.Н. Государственный контроль над преступностью: дисс... докт. юрид. наук. Нижний Новгород, 1997. С. 310-311.

20. Баликоева Л.М. Полномочия органов местного самоуправления по обеспечению правопорядка: автореф. дисс... канд. юрид. наук. М., 2013. С. 9-10.

21. Шугрина Е.С. Правовое регулирование муниципального контроля в Российской Федерации. // Административное и муниципальное право. 2011. 8. С. 26-37.

22. Сергеев Д.Б. Муниципальное образование как часть социально-юридического механизма обеспечения прав человека // Административное и муниципальное право. 2012. 12. С. 5-16.

\section{References (transliterated):}

1. Bezrukov A.V. Konstitutsionno-pravovye aspekty osushchestvleniya zakonodatel'noi vlasti po obespecheniyu pravoporyadka v Rossii: monografiya. M., 2015. S. 3-43

2. Vissarov A.V. Pravoporyadok i sub"ekty ego obespecheniya (teoretiko-pravovoi aspekt): avtoref. dis.... kand. yurid. nauk. M., 2003. S. 17-18.

3. Zubov I.N. Gosudarstvenno-pravovye i organizatsionnye problemy funktsionirovaniya i razvitiya sistemy MVD Rossii: diss. ... dokt. yurid. nauk. SPb, 1999. S. 9-10.

4. $\quad$ Pravovoe polozhenie politsii MVD Rossii: uchebnik / pod red. F.P. Vasil'eva. M., 2014. S. 258-268.

5. Chistoborodov I.G. Administrativno-pravovoe obespechenie organami vnutrennikh del pravoporyadka i obshchestvennoi bezopasnosti v period podgotovki i provedeniya izbiratel'nykh kampanii: dis. ... kand. yurid. nauk. M., 2013. S. 13-14.

6. Krasinskii V.V. Pravovoe obespechenie zashchity konstitutsionnogo stroya Rossii v izbiratel'nom protsesse: monografiya. M., 2010. S. 161-162.

7. Fedotova Yu.G. Kontrol'nye polnomochiya izbiratel'nykh komissii v mekhanizme obespecheniya bezopasnosti Rossiiskoi Federatsii // Gosudarstvennaya vlast' i mestnoe samoupravlenie. 2015. № 2. S. 34-36.

8. Pereverzev E.A. Pravovye i organizatsionnye osnovy vzaimodeistviya organov vnutrennikh del i organov mestnogo samoupravleniya: dis. ... kand. yurid. nauk. M., 2001.

9. Skripkina Yu.G. Vzaimodeistvie organov mestnogo samoupravleniya s organami vnutrennikh del po okhrane obshchestvennogo poryadka na territorii munitsipal'nogo obrazovaniya: konstitutsionno-pravovye i organizatsionnye voprosy: avtoref. dis. ... kand. yurid. nauk. SPb., 2009. S. 25-26.

10. Sovmestnoe informatsionnoe pis'mo General'noi prokuratury Rossii, MVD Rossii, FSB Rossii, Sledstvennogo komiteta Rossii, FSKN Rossii i FTS Rossii ot 5 oktyabrya 2012 g. N 32/1/9016/8/K/8-4451/208-35208/VI-4351/01-40/50159 // SPS Konsul'tant Plyus.

11. Stupachenko E.V. Sostav uchastnikov postoyanno deistvuyushchikh koordinatsionnykh soveshchanii po obespecheniyu pravoporyadka v sub"ektakh RF // Zakonnost'. 2014. № 7.

12. Stupachenko E.V. Istoricheskie i pravovye aspekty sozdaniya postoyanno deistvuyushchikh koordinatsionnykh soveshchanii po obespecheniyu pravoporyadka v sub"ektakh Rossiiskoi Federatsii // Gosudarstvennaya vlast' i mestnoe samoupravlenie. 2014. № 11. S.40-41.

13. Sbornik prikazov i instruktsii General'nogo prokurora SSSR. Chast' 1. M., 1976. S. 37.

14. Fadeev V.I. Stabil'nost' i razvitie Konstitutsii Rossiiskoi Federatsii // Vestnik Moskovskogo universiteta. Seriya 11. Pravo. 2014. № 1. S.52-53.

15. Skripkin G.F. K voprosu ob okhrane obshchestvennogo poryadka organami mestnogo samoupravleniya v svete prinyatiya Zakona o politsii // Vestnik Moskovskogo universiteta MVD Rossii. 2012. № 1. S. 165-166. 
16. Min'kovskii G.M. O ponyatii i strukture munitsipal'noi militsii // Munitsipal'naya militsiya: problemy organizatsii i pravovogo obespecheniya, zarubezhnyi opyt. M., 1991. S. 35-37.

17. Starostin S.A. Nuzhna li munitsipal'naya militsiya Rossiiskoi Federatsii // Nauchnyi portal MVD Rossii. 2014. №4. S. 80-82.

18. Shikhov E.Yu. Organizatsiya mestnoi (munitsipal'noi) militsii v sisteme upravleniya (po materialam goroda Moskvy): diss.... kand. yurid. nauk. M., 1995. S.7-10.

19. Kharitonov A.N. Gosudarstvennyi kontrol' nad prestupnost'yu: diss... dokt. yurid. nauk. Nizhnii Novgorod, 1997. S. 310-311.

20. Balikoeva L.M. Polnomochiya organov mestnogo samoupravleniya po obespecheniyu pravoporyadka: avtoref. diss... kand. yurid. nauk. M., 2013. S. 9-10.

21. Shugrina E.S. Pravovoe regulirovanie munitsipal'nogo kontrolya v Rossiiskoi Federatsii. // Administrativnoe i munitsipal'noe pravo. 2011. 8. C. 26-37.

22. SergeevD.B.Munitsipal'noeobrazovaniekakchast'sotsial'no-yuridicheskogomekhanizmaobespecheniyapravcheloveka// Administrativnoe i munitsipal'noe pravo. 2012.12. C. 5-16. 